\title{
BMJ Open Social deprivation, gender and obesity: multiple stigma? Results of a population survey from Germany
}

\author{
Anna Christin Makowski, ${ }^{1}$ Tae Jun Kim, ${ }^{1}$ Claudia Luck-Sikorski, ${ }^{2,3}$ \\ Olaf von dem Knesebeck ${ }^{1}$
}

To cite: Makowski AC, Kim TJ, Luck-Sikorski C, et al. Social deprivation, gender and obesity: multiple stigma? Results of a population survey from Germany. BMJ Open 2019;9:e023389. doi:10.1136/ bmjopen-2018-023389

- Prepublication history and additional material for this paper are available online. To view please visit the journal (http:// dx.doi.org/10.1136/bmjopen2018-023389)

Received 4 April 2018 Revised 14 February 2019 Accepted 22 February 2019

Check for updates

(C) Author(s) (or their employer(s)) 2019. Re-use permitted under CC BY-NC. No commercial re-use. See rights and permissions. Published by BMJ.

${ }^{1}$ Department of Medical Sociology, University Medical Center Hamburg-Eppendorf,

Hamburg, Germany

${ }^{2}$ Integrated Research and

Treatment Center (IFB) Adiposity Diseases, University of Leipzig,

Leipzig, Germany

${ }^{3}$ SRH University of Applied Health Sciences, Gera, Germany

Correspondence to

Tae Jun Kim;

t.kim@uke.uni-hamburg.de

\section{ABSTRACT}

Objectives Individuals with obesity are subject to stigmatisation, resulting in discrimination. Studies focusing on obesity stigma often do not account for social conditions that also may be associated with stigmatisation. Following an intersectional approach, social categories such as gender and socioeconomic status (SES) can interact and form a basis for multiple stigma. The present study analyses differences in public obesity stigma depending on gender and SES, as well as possible interdependencies between these social categories. Design Representative cross-sectional telephone survey. Participants 692 randomly selected adults ( $\geq 18$ years) in Germany.

Methods Different vignettes were presented, depicting a lawyer (male/female) or a janitor/cleaner (male/female) with obesity. Following the vignette, different components of stigma were assessed: (1) fat phobia, (2) emotional reactions to a person with obesity and (3) desire for social distance. Associations between gender, SES and stigma components were tested in multiple linear regression analyses.

Results A low SES in the obesity vignette (janitor/cleaner) was significantly associated with higher fat phobia scores as well as desire for social distance, compared with the vignette with a person with obesity and a high SES (lawyer). Being a male with obesity was significantly associated with more pronounced negative emotional reactions and greater desire for social distance. There were no significant interaction effects between gender and SES.

Conclusions Results support the hypothesis of multiple stigma. Being male or of low SES was significantly associated with more pronounced negative attitudes in the German public. Following the concept of intersectionality, our findings indicate that obesity stigma can exacerbate pre-existing inequalities. This needs to be considered in development and implementation of prevention and antistigma measures.

\section{INTRODUCTION}

The proportion of people who are overweight or live with obesity has increased continuously over the past decades. In Germany, the current Health Interview and Examination Survey for Adults reports a prevalence rate of obesity (defined as body mass index,

\section{Strengths and limitations of this study}

This is the first study analysing socioeconomic status (SES) and gender in the context of public obesity stigma.

- Analyses are based on a national telephone survey not only relying on landline but also including mobile-only users all over Germany.

- Prerecorded audio vignettes were used to identify additional stigma effects. To test for a separation of obesity stigma from the stigma associated with gender and SES, a neutral control vignette would have been necessary.

- Although vignettes are a frequently used method in stigma research, they need to be short and bear the risk of not conveying a holistic picture of an individual with obesity and different social characteristics.

BMI $\geq 30 \mathrm{~kg} / \mathrm{m}^{2}$ ) of approximately $24 \%$. $^{2}$ The aetiology of obesity is multifaceted, different factors such as behavioural, biological, psychosocial, context-related or prenatal conditions concur. ${ }^{3}$ However, poor diet and sedentary behaviour are often erroneously seen as the primary reason for overweight. ${ }^{4}$ This, in turn, lays the focus on individual responsibility and fosters public stereotypes of laziness and weak will. According to attribution theory, believing the condition to be under a person's control determines greater stigmatising reactions. ${ }^{5}$ The public misconception of causes of overweight and obesity is common and contributes to the expression of obesity stigma. ${ }^{6}$ Individuals with overweight or obesity display a physical 'mark' that sets them apart from others. Link and Phelan ${ }^{7}$ have provided a process model, in which stigma is conceptualised as several distinct, but interrelated steps: differences between social groups are distinguished and labelled. These labels are linked to stereotypes (undesired characteristics) that form the basis of a separation of 'us' and 'them'. Thusly labelled individuals experience status loss and discrimination in a context in which power is exercised. 
There is a public recognition of obesity as a chronic condition and it is a classified disease in some countries (but not Germany). ${ }^{8}$ Nevertheless, individuals with obesity experience discrimination in daily life, which, in turn, reinforces negative stereotypes and stigmatising processes. ${ }^{7}$ Ascribing negative attributes, such as unintelligent, lack of self-discipline or emotionally instable ${ }^{910}$ to persons who are obese, activates processes that result in discrimination in different settings. This could be shown for the education and employment sector as well as personal relationships. ${ }^{10}$ Furthermore, stigmatising attitudes and discrimination are present in the healthcare sector, possibly leading to the avoidance of necessary treatment. ${ }^{11}$ The adverse health consequences of obesity stigma have been shown on psychological (eg, depression, self-esteem) and physical (eating behaviour, physical activity, cardiovascular health outcomes) levels. ${ }^{10}$

One German study found that about one-fourth of the general public displays stigmatising attitudes regarding the 'Weight Control/Blame' subscale from the Antifat Attitudes Test. ${ }^{12}$ High levels of responsibility for becoming obese are attributed to the individual, which is associated with the belief that the individual should be liable for treatment costs to a great extent. ${ }^{13}$ Sikorski et al examined emotional reactions and social distance towards individuals with obesity and found that the most rejected domains were personal ability as well as social interaction. ${ }^{14}$

In terms of gender differences, studies reported higher weight bias internalisation ${ }^{15}$ and greater risk for weight/ height discrimination ${ }^{16}$ among women. In children and adolescents, girls with overweight have been found to be subject to teasing and social marginalisation. ${ }^{17}{ }^{18}$ Similar results are presented by Fikkan and Rothblum, ${ }^{19}$ who found women with obesity to be more stigmatised in education and employment sectors than men. However, gender differences in obesity stigma have rarely been examined, and results are not consistent. ${ }^{20}$

In recent years, stigma research has paid increased attention to multiple social identities and their interaction to influence stigmatisation. This intersectional approach allows examining how multiple social categories, for example, being categorised as 'female', 'black' or both, interact to produce or protect against health risks or discrimination. ${ }^{15}$ This may be referred to as 'multiple stigma' ${ }^{21}$ or 'double disadvantage'. ${ }^{22}$ These concepts suggest that a person can belong to different, possibly stigmatised social groups which exerts cumulative effects. ${ }^{23}$ When it comes to obesity stigma at the intersection of gender and race, few studies have been conducted and results were inconsistent. Himmelstein et $a l^{15}$ found no divergences in obesity stigma according to race or gender, whereas Puhl et al found that African-American females with obesity evoked higher ratings of dislike and social distance than Caucasian females with obesity. ${ }^{24}$ It has been postulated by Grey that severe and extreme obesity compounds pre-existing socioeconomic inequalities in context of vulnerability. ${ }^{25}$
However, to date, no study has focused on the possible additive or multiple effects of gender and socioeconomic status (SES) in the context of obesity stigma. This is astonishing, as there are socioeconomic inequalities in the prevalence of obesity. ${ }^{26}$ This also holds true for Germany, where obesity is more common among children and adults who are of low SES. Women in this group appear to be excessively affected by obesity. ${ }^{27}$

Against this background, we analyse differences in public stigma towards low versus high SES persons as well as female versus male persons with obesity. By incorporating the interaction of gender $\times$ SES, we additionally examine possible interdependencies and their associations with obesity stigma.

\section{METHODS}

\section{Study design and sample}

Analyses are based on a national telephone survey (computer-assisted telephone interview), conducted between March and April 2017. The sampling was based on data of the Association of German Market and Social Research, which includes registered as well as nonregistered telephone numbers via random digital dialling. Already in 2010, around 13\% of adults (age 16 years and older) in Germany did not have access to landline and solely used a mobile phone. ${ }^{28}$ As this proportion has increased since 2010 and in order to increase the probability to reach persons who are rarely at home, a share of $30 \%$ mobile numbers was incorporated in the initial sample. To ensure a sample representative of the German population, all regions in Germany were included.

Regarding mobile numbers, target persons were the owner or main user of the mobile phone. The connection was considered a neutral drop out if the respondent was younger than 18 years. In households that were contacted via landline, the Kish-Selection-Grid ${ }^{29}$ was applied to randomly select a person from this household. The interviewer collected the age and gender of everyone in the household that was eligible for the survey and then randomly selected one person from that list. At the start of the interview, respondents were informed that the survey's focus was on nutrition, health and well-being.

The overall sample of this study consisted of 1401 persons. To obtain this number, 2849 people were randomly selected (net sample). Of these, 862 persons $(30.25 \%)$ refused to participate in the interview. Further, 586 persons $(20.57 \%)$ could not be reached. This led to a total response rate of $49.18 \%$. Previous telephone interview studies have reached similar rates ${ }^{30}$ and the response can be regarded satisfactory for telephone surveys in Germany. ${ }^{32}$ In the study, eight different vignettes were used. The present analyses focus on four vignettes depicting a lawyer (male/female) or a janitor/ cleaner (male/female) with obesity, resulting in a subsample of $n=692$ under study. 


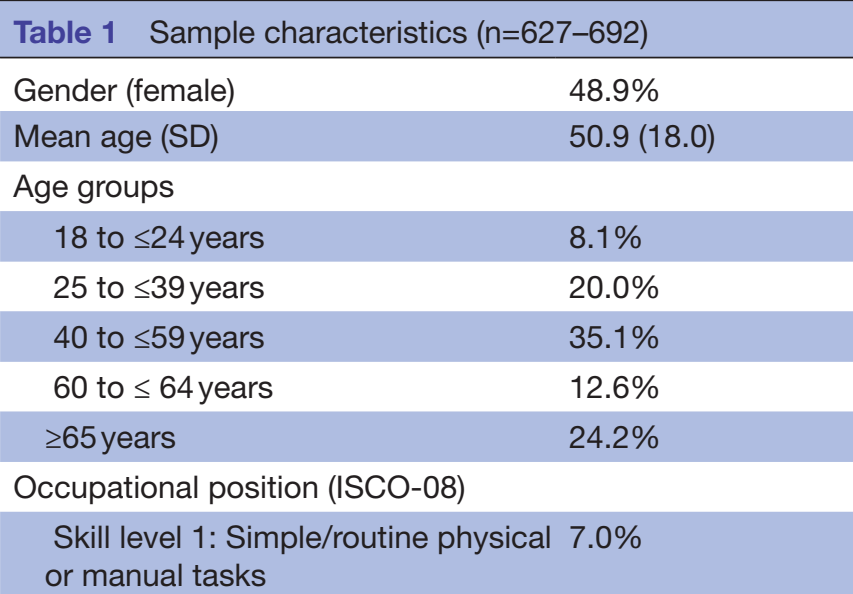

\section{or manual tasks}

Skill level 2: Operating machinery $\quad 45.5 \%$ and electronic equipment

\section{Skill level 3: Complex technical and $27.1 \%$} practical tasks
Skill level 4: Complex problem-
$20.3 \%$
solving, decision-making, creativity

\begin{tabular}{|c|c|}
\hline \multicolumn{2}{|l|}{ Weight status according to BMI } \\
\hline Underweight ( $\leq 18.49)$ & $2.1 \%$ \\
\hline Normal weight (18.50-24.99) & $42.5 \%$ \\
\hline Overweight (25.00-29.99) & $34.2 \%$ \\
\hline Obese $(\geq 30.00)$ & $21.2 \%$ \\
\hline $\begin{array}{l}\text { Contact to someone who is } \\
\text { overweight (yes) }\end{array}$ & $84.4 \%$ \\
\hline \multicolumn{2}{|l|}{$\begin{array}{l}\text { Obesity stigma scales, mean (SD), } \\
\text { median [IQR] }\end{array}$} \\
\hline Fat Phobia Scale* & $\begin{array}{l}3.34(0.49), 3.29 \\
{[3-3.64]}\end{array}$ \\
\hline $\begin{array}{l}\text { Negative emotional reactions } \\
\text { scale† }\end{array}$ & $\begin{array}{l}10.29(3.17), 10[8- \\
12]\end{array}$ \\
\hline Positive emotional reactions scaleł & 6.91 (1.86), $7[6-8]$ \\
\hline Desire for social distance scale§ & $\begin{array}{l}12.72(1.86), 13[9- \\
15]\end{array}$ \\
\hline
\end{tabular}

*Fat phobia scale comprised of 14 items, ranging from 1 to 5 , values $>2.50$ indicate fat phobia.

†Negative emotional reaction scale comprised of six items; sum scale ranging from 6 to 24 .

$\ddagger$ Positive emotional reaction scale comprised of three items; sum scale ranging from 3 to 12 .

$\S$ Desire for social distance scale comprised of 7 items, sum scale ranging from 7 to 28 .

BMI, body mass index; ISCO-08, International Standard Classification of Occupation 08.

The Ethics Commission of the Medical Association in Hamburg approved this study (No. PV5421). Since the interviews were telephone based, the respondents were verbally informed about the study and asked for consent to participate. Participants' consent and refusal were documented. As we used data from a population survey, patients were not involved in the development and design of the research question and the study.

\section{Instruments}

Vignette manipulation

Vignettes have been frequently applied in the social sciences to investigate attitudes or intended behaviour. ${ }^{33}$ In stigma research, they have been used to convey realistic pictures of an individual, for example, with depression, schizophrenia or obesity. ${ }^{34} 35$

In the present study, all prerecorded audio vignettes conveyed the same information while two characteristics were varied: gender (female/male) and occupational position as an indicator of SES (low = janitor or cleaner/ high $=$ lawyer $)$. This resulted in four different case stories that described an individual with obesity (please see online appendix). One vignette was randomly assigned to each respondent, resulting in about 175 respondents per vignette. Weight and height were stated, yielding a BMI of approximately $32 \mathrm{~kg} / \mathrm{m}^{2}$. This was further emphasised by the comment that the person 'is severely overweight'. A trained speaker audio-recorded the case stories. To neutralise possible interviewer effects, the files were directly played to the respondents from the computer via telephone line. Preceding the presentation of the vignette, there was a set of questions related to respondents' own experience with overweight. This was self-reported weight and height, if the respondent has ever been overweight, tried to lose weight or has personal contact to persons with obesity.

\section{Obesity stigma}

To assess stigmatising attitudes towards the person described in the vignette, the short form of the Fat Phobia Scale (FPS) by Bacon et $a l^{36}$ was used. This comprised 14 items of the original 50-item scale. ${ }^{37}$ The short version demonstrated excellent reliability and was strongly correlated with the long form. Moreover, the 14-item scale accounted for the largest amount of variance in factor analysis. ${ }^{36}$ On a five-point semantic differential scale, 14 pairs of adjectives are introduced that capture common beliefs about people who are obese. The FPS short form has been translated and applied in German by LuckSikorski and colleagues. ${ }^{35}$ Principal component analysis with varimax rotation yielded a four-factorial solution, with the eigenvalue of the fourth factor barely exceeding 1. Similar to a validation study for the German short version of the FPS, the first factor explained the greatest share of variation $(25.58 \%$, second factor; $10.80 \%$, third factor; $8.19 \%$, fourth factor $7.31 \%$ ) which is why a one-factorial solution is supported. ${ }^{38}$ Following Bacon $e t$ $a l,{ }^{36}$ some items were inverted where necessary so that a higher score indicates greater fat phobia. The sum score was divided by the number of items so that the score ranges from 1 to 5 . Values $<2.5$ indicate positive attitudes and values $\geq 2.5$ represent negative attitudes towards a person with obesity. ${ }^{39}$ Cronbach's $\alpha$ for the FPS was 0.77 .

Emotional reactions were assessed by nine items representing different ways of emotionally responding to the person described in the vignette. Six items were derived from a scale used in studies on mental illness stigma ${ }^{40}$ 
Table 2 Fat Phobia Scale (single items and scale): differences according to gender and SES in the vignette (mean values, SD)

\begin{tabular}{|c|c|c|c|c|c|c|}
\hline \multirow[b]{2}{*}{ Pair of adjectives } & \multicolumn{3}{|l|}{ Gender } & \multicolumn{3}{|l|}{ SES } \\
\hline & $\begin{array}{l}\text { Female } \\
(n=337-348)\end{array}$ & $\begin{array}{l}\text { Male } \\
(n=306-316)\end{array}$ & P value* & $\begin{array}{l}\text { Low } \\
\text { janitor/cleaner } \\
(n=317-327)\end{array}$ & $\begin{array}{l}\text { High } \\
\text { lawyer } \\
(n=326-337)\end{array}$ & P value* \\
\hline Industrious-lazy† & $2.55(0.92)$ & $2.83(0.81)$ & $<0.001$ & $2.68(0.87)$ & $2.69(0.89)$ & 0.667 \\
\hline Has willpower-no willpower† & $3.28(0.97)$ & $3.21(1.04)$ & 0.602 & $3.48(0.98)$ & $3.03(0.97)$ & $<0.001$ \\
\hline Attractive-unattractive $†$ & $3.33(1.00)$ & $3.42(0.94)$ & 0.160 & $3.43(1.05)$ & $3.32(0.90)$ & 0.149 \\
\hline Fast-slow† & $3.25(1.01)$ & $3.47(0.99)$ & 0.002 & $3.32(1.06)$ & $3.39(0.96)$ & 0.592 \\
\hline $\begin{array}{l}\text { Having endurance-having no } \\
\text { endurance } †\end{array}$ & $3.41(1.13)$ & $3.37(1.04)$ & 0.297 & $3.39(1.10)$ & $3.40(1.07)$ & 0.688 \\
\hline Active-inactive $†$ & $3.36(0.98)$ & $3.38(1.06)$ & 0.328 & $3.38(1.06)$ & $3.35(0.97)$ & 0.650 \\
\hline Shapely-shapeless $†$ & $3.41(1.15)$ & $3.21(1.17)$ & 0.098 & $3.40(1.16)$ & $3.31(1.17)$ & 0.753 \\
\hline Undereats-overeats $†$ & $3.87(0.91)$ & $3.95(0.90)$ & 0.306 & $3.91(0.93)$ & $3.90(0.89)$ & 0.883 \\
\hline Secure-insecure $†$ & $3.01(1.06)$ & $2.81(1.03)$ & 0.027 & $3.24(1.02)$ & $2.61(0.98)$ & $<0.001$ \\
\hline High self-esteem-low self-esteem† & $3.10(1.05)$ & $2.83(1.05)$ & $<0.001$ & $3.28(1.00)$ & $2.67(1.02)$ & $<0.001$ \\
\hline Fat Phobia Scale† & $3.31(0.48)$ & $3.32(0.50)$ & 0.995 & $3.40(0.51)$ & $3.22(0.46)$ & $<0.001$ \\
\hline
\end{tabular}

*Mann-Whitney U test

†Semantic differential scales and mean FPS ranging from 1 to 5 , values $>2.50$ indicate fat phobia.

SES, socioeconomic status.

while three items were developed based on common stereotypes of obesity. The items were coded from 1 'completely disagree' to 4 'completely agree'. A principal component analysis with varimax rotation yielded two different factors. The first factor, termed negative emotional reactions, was comprised of the following six items: 'I react angrily', 'I feel annoyed', 'This triggers incomprehension with me', 'I feel repelled', 'I feel disgust' and 'I think this is unaesthetic'. The items 'I feel pity', 'I feel sympathy' and 'I want to help' loaded on the second factor of positive emotional reactions. Together, the two factors accounted for $50.9 \%$ of variance. Two sum scores were computed, Cronbach's $\alpha$ was 0.78 for negative (six items), and 0.47 for positive emotional reactions (three items).

Desire for social distance was assessed by a scale developed by Link et $a l^{41}$ a modified version of the Bogardus Social Distance Scale. ${ }^{42}$ The instrument contains seven items that represent different social relationships (eg, neighbour, colleague or childcarer). On a four-point Likertscale, respondents were asked to indicate to what extent they would accept the person described in the vignette. A principal component analysis with varimax rotation was carried out, yielding a single factor that explained $55.1 \%$ of variance. Cronbach's $\alpha$ was 0.86 . Again, a sum score was computed, with higher scores indicating greater desire for social distance. The distribution of the stigma sum scales across the sample is shown in table 1 .

\section{Statistical analyses}

The analyses were performed using SPSS V.22. ${ }^{43}$ To test for significant mean differences between groups regarding single items and scales, Mann-Whitney $\mathrm{U}$ tests were applied. This nonparametric test was conducted, since Kolmogorow-Smirnow tests revealed that responses to the stigma items did not follow a normal distribution. Determinants of stigmatising attitudes were introduced into multiple linear regression models. We analysed two main effects presented in the vignette: SES (janitor or cleaner/ lawyer) and gender (female/male). To take into account possible interdependencies, the interaction effect of SES $\times$ gender was also introduced into the models. All models were controlled for respondents' characteristics. Age and BMI were entered as continuous variables. The respondents' occupational position was expressed in skill levels according to the International Standard Classification of Occupation (ISCO-08). ${ }^{44}$ Other variables were the respondents' gender and personal contact to individuals who are obese.

In all analyses, the response options 'prefer not to say' and 'don't know' were treated as missing values. Exact $p$ values are reported. In view of the number of tests, values of $p<0.01$ were regarded as statistically significant.

\section{Patient involvement}

No patients were involved in this study. 
Table 3 Emotional reactions (single items and scales): differences according to gender and SES in the vignette (mean values, $\mathrm{SD})$

\begin{tabular}{|c|c|c|c|c|c|c|}
\hline & \multicolumn{3}{|l|}{ Gender } & \multicolumn{3}{|l|}{ SES } \\
\hline & $\begin{array}{l}\text { Female } \\
(n=327-350)\end{array}$ & $\begin{array}{l}\text { Male } \\
(n=293-315)\end{array}$ & P value* & $\begin{array}{l}\text { Low } \\
\text { janitor/cleaner } \\
(n=299-326)\end{array}$ & $\begin{array}{l}\text { High } \\
\text { lawyer } \\
(n=321-338)\end{array}$ & $P$ value* \\
\hline Annoyed $\dagger$ & $1.56(0.72)$ & $1.59(0.70)$ & 0.290 & $1.65(0.79)$ & $1.50(0.62)$ & 0.056 \\
\hline Angry† & $1.36(0.64)$ & $1.55(0.71)$ & $<0.001$ & $1.52(0.71)$ & $1.38(0.64)$ & 0.005 \\
\hline Incomprehension† & $1.88(0.89)$ & $2.04(0.83)$ & 0.006 & $2.05(0.87)$ & $1.87(0.85)$ & 0.012 \\
\hline Disgust† & $1.41(0.66)$ & $1.53(0.66)$ & 0.002 & $1.51(0.69)$ & $1.42(0.94)$ & 0.078 \\
\hline Unaesthetic $†$ & $2.01(0.94)$ & $2.15(0.87)$ & 0.022 & $2.08(0.87)$ & $2.07(0.95)$ & 0.919 \\
\hline Negative emotional reactions scaleł & $9.67(3.06)$ & $10.54(3.24)$ & 0.001 & $10.43(3.23)$ & $9.74(3.05)$ & 0.012 \\
\hline Sympathy† & $2.58(0.81)$ & $2.53(0.78)$ & 0.769 & $2.54(0.82)$ & $2.57(0.77)$ & 0.884 \\
\hline
\end{tabular}

*Mann-Whitney U test

†Single items ranging from 1 to 4 .

†Negative emotional reaction scales comprised of six items; sum scale ranging from 6 to 24 .

§Positive emotional reaction scale comprised of three items; sum scale ranging from 3 to 12 .

SES, socioeconomic status.

\section{RESULTS}

Sociodemographic characteristics of the analysed sample are briefly presented in table 1 . The male:female ratio is relatively even, which is similar to the general adult population in Germany according to the official statistics. ${ }^{45}$ In terms of age, people aged 25-39 years are under-represented and people aged 60-64 years are over-represented in the sample compared with the distribution in the official statistics. ${ }^{46}$ Almost half of the respondents work in occupational positions that are regarded skill level 2 when referring to ISCO. ${ }^{44}$ Regarding weight status, more than $50 \%$ of the respondents reported overweight or obesity. The share of those with overweight/obesity corresponds to numbers obtained by other representative studies in Germany. ${ }^{2}$ The vast majority $(84.4 \%)$ has or had personal contact to someone who is overweight.

In tables 2-4, differences in the mean stigma values depending on SES and gender presented in the vignette

Table 4 Desire for social distance (single items and scale): differences according to gender and SES in the vignette (mean values, SD)

\begin{tabular}{|c|c|c|c|c|c|c|}
\hline & \multicolumn{3}{|l|}{ Gender } & \multicolumn{3}{|l|}{ SES } \\
\hline & $\begin{array}{l}\text { Female } \\
(n=332-350)\end{array}$ & $\begin{array}{l}\text { Male } \\
(n=292-312)\end{array}$ & P value* & $\begin{array}{l}\text { Low } \\
\text { janitor/cleaner } \\
(n=307-324)\end{array}$ & $\begin{array}{l}\text { High } \\
\text { lawyer } \\
\text { (317-338) }\end{array}$ & P value* \\
\hline Tenant $†$ & $1.71(0.92)$ & $1.96(0.86)$ & $<0.001$ & $1.98(0.98)$ & $1.68(0.78)$ & 0.001 \\
\hline Colleague $†$ & $1.39(0.57)$ & $1.48(0.61)$ & 0.012 & $1.43(0.54)$ & $1.42(0.63)$ & 0.546 \\
\hline In-law† & $1.79(0.90)$ & $1.90(0.79)$ & 0.003 & $1.98(0.89)$ & $1.71(0.78)$ & $<0.001$ \\
\hline Introduce friend $†$ & $1.74(0.82)$ & $2.25(0.95)$ & $<0.001$ & $2.08(0.92)$ & $1.88(0.90)$ & 0.008 \\
\hline Recommend for job† & $1.83(0.84)$ & $2.04(0.81)$ & $<0.001$ & $2.03(0.83)$ & $1.83(0.82)$ & 0.011 \\
\hline $\begin{array}{l}\text { Desire for social distance } \\
\text { scale } \neq\end{array}$ & $11.66(4.12)$ & $13.15(4.00)$ & $<0.001$ & $13.03(4.14)$ & $11.72(4.03)$ & $<0.001$ \\
\hline
\end{tabular}

*Mann Whitney U test

†Single items ranging from 1 to 4 .

fDesire for social distance scale comprised of 7 items, sum scale ranging from 7 to 28 .

SES, socioeconomic status. 
are reported. Regarding the fat phobia items, the adjective low self-esteem was ascribed to the female vignette significantly more often (respective means were 3.10 for the female vignette and 2.83 for the male vignette, table 2). In contrast, lazy, slow and self-indulgent were significantly more often attributed to the male vignette. Comparing low and high SES, a homogeneous picture emerged. A low SES was significantly associated with greater negative attitudes, expressing individual responsibility (no willpower, poor self-control, weak) as well as insecurity and low self-esteem when compared with high SES.

Regarding emotional reactions (table 3), the comparison of gender in the vignette showed that males with obesity evoked significantly more negative emotional reactions on four out of six items as well as on the subscale for negative emotions (respective means were 9.67 for the female vignette and 10.54 for the male vignette). In terms of SES, a cleaner/janitor with obesity evoked significantly more feelings of anger but also more positive emotional reactions, compared with a lawyer with obesity.

A consistent picture emerged when comparing desire for social distance according to the person's gender in the vignette (table 4). Males with obesity were met with significantly greater levels of rejection in most aspects of social distance. Gender difference was also significant for the desire for social distance scale (13.15 for males and 11.66 for females). Similarly, a person with obesity and a low SES evoked greater desire for social distance concerning four of seven items. Also, the desire for social distance scale significantly differed between the SES vignettes (13.03 for low SES and 11.72 for high SES).

The results of multiple linear regression analyses are reported in table 5. While controlling for respondents' characteristics, a significant main effect of SES emerged regarding fat phobia $(\beta=0.173)$. Being a janitor or cleaner with obesity was associated with significantly increased fat phobia compared with lawyers. Regarding positive emotional reactions, there were no significant associations with either gender or SES. However, male persons with obesity were confronted with more negative emotional reactions than females $(\beta=-0.151)$. In terms of desire for social distance, both main effects were statistically significant. Being either a male or a janitor/cleaner with obesity was significantly associated with greater desire for social distance. In none of the models did the interaction effect of gender $\times$ SES attain statistical significance (table 5).

\section{DISCUSSION}

The concept of multiple stigma suggests that a person can belong to different potentially stigmatised groups, experiencing an aggregation of disadvantages and discrimination. ${ }^{23}$ Applying this approach to the present study, this would mean that because of their group affiliation (eg, being female and of low SES), individuals suffer multiple stigma when confronted with the burden of obesity. 
Similarly, the framework of intersectionality describes the interdependent relationship between different social identities and structural inequities. ${ }^{47}$ Multiple social categories interact and produce or protect against discrimination. In light of this, obesity stigma can reinforce pre-existing inequalities because of SES and/or gender.

The present study is the first to analyse the possible multiple stigma of gender, SES and obesity. Following an intersectional approach, it was analysed whether main effects or the interaction of social categories possibly reinforce obesity stigma, implying a double or multiple disadvantage for certain individuals. While there were no statistically significant interaction effects of categories, we found distinct differences in obesity stigma dependent on gender with regard to different stigma components. Males with obesity were met with more negative emotional reactions and social distance. This contradicts some previous studies that found (young) women with overweight or obesity to be met with greater stigmatisation than men. ${ }^{15-19}$ The predominance of overly thin women in the media and the promotion of a slim beauty ideal for females can have different effects on the stigmatisation of women and men with obesity. ${ }^{20}$ Nevertheless, over the past decade, a trim and muscular male body image has come to the fore in most Western societies, shaping a new perspective on body image dissatisfaction and obesity stigma also among men. ${ }^{49}$ Men have been found to be similarly stigmatised as women for being heavy, ${ }^{20}$ and the concern about body image is associated with increased eating pathology in both men and women. ${ }^{50}$

Regarding SES and obesity, the study revealed significant differences in public attitudes in several stigma components under study. Those of low SES were rated less favourably with regard to fat phobia and desire for social distance when compared with persons with high SES. On the other hand, individuals with low SES were also met with significantly greater prosocial feelings. It is possible that, next to obesity, the status of a cleaner/ janitor is linked to characteristics (eg, economic hardship) that evoke pity among respondents. After the adjustment of respondents' characteristics in the multivariate analyses (gender, age, BMI, occupational position as well as contact to an individual with obesity), however, only the associations with fat phobia and social distance were found to be significant.

Following the concept of intersectionality, and against the background of a disproportionate distribution of obesity (higher prevalence among females of low SES), one could have expected significant interaction effects in multivariate analyses. We were not able to verify this assumption. However, significant main effects of gender and SES indicate a double stigma to the disadvantage of males as well as individuals with a low SES who suffer from obesity.

Some limitations need to be mentioned and discussed when evaluating our findings. More than half of the individuals eligible for the study were not available or refused to participate. Although participation rates around $50 \%$ can be regarded satisfactory for telephone surveys,${ }^{32}$ we cannot rule out selection bias due to nonresponse. With respect to internal consistency, Cronbach's $\alpha$ for most scales was good or acceptable. Only the subscale of positive emotional reactions exhibited limited reliability, which could be due to the relatively small number of items. In this case, it is recommended to use the mean inter-item correlation as an indicator for acceptability, which was 0.22 in the present sample. A satisfactory range is said to be $0.2-0.4 .^{51}$ Furthermore, no conclusions on causal relationships can be drawn as our data are based on a cross-sectional design. Similar to other studies in stigma research, we used vignettes to explore possible multiple stigma of obesity. On the one hand, these should not be too long. On the other hand, only varying one sentence to express different social conditions might have been too short to convey a holistic picture of the individual, or to be kept in mind throughout the whole interview. Also, vignettes had to be understandable for the general population. Therefore, we decided not to report the BMI and not to use the term 'obese'. In this regard, it can be considered a limitation that the vignettes lack medical accuracy. Moreover, due to time constraints, every respondent only received one vignette. The lack of a neutral control condition impedes the interpretation of results. For example, it remains unclear whether respondents associate adjectives such as low self-esteem or insecurity with the fact that the individual in the vignette presented with obesity or pursues the profession of a janitor when compared with a lawyer. This is a limitation that has to be considered when interpreting our findings as an indication of multiple or double stigma. Finally, sample size may have been too small to detect significant interaction effects.

Differences in stigma based on gender and SES indicate that obesity can exacerbate pre-existing inequalities. The presence of obesity stigma could be shown in many domains of daily life, for example, education, work, personal and healthcare. ${ }^{10}{ }^{11}$ Stigmatisation is a risk factor for physical and psychological health problems such as depression, body dissatisfaction and low self-esteem. Instead of motivating individuals to lose weight, stigma is associated with additional weight gain $^{6}$ and underutilisation of healthcare. ${ }^{11}$ This implies a vicious circle of mutually reinforcing negative conditions. The manifold effects of obesity stigma require actions in all kinds of professional disciplines, for example, among physicians, dieticians and scientists in various fields. To counteract stigma, the topic should be the subject of discussion in obesity intervention measures, and anti-stigma messages have to be incorporated into obesity prevention campaigns. Our results underline the need to consider the social dimension of obesity stigma. In acknowledging the interrelation of social conditions and existing structures, future research should derive tailored measures 
to encounter obesity stigma and its related adverse physical and psychological health outcomes.

Contributors ACM undertook the statistical analyses and wrote the first draft of the manuscript. OvdK conceived the study design and contributed to the manuscript. TJK and CLS contributed to the questionnaire and critically revised the manuscript.

Funding This study is part of the joint research project 'Nutrition, Health and Modern Society: Germany and the USA' and is funded by the Volkswagen Foundation.

Competing interests None declared.

Patient consent for publication Not required

Ethics approval Ethics Commission of the Medical Association Hamburg approved the data collection procedure (No. PV5421).

Provenance and peer review Not commissioned; externally peer reviewed.

Data sharing statement Data are available by request from the corresponding author.

Open access This is an open access article distributed in accordance with the Creative Commons Attribution Non Commercial (CC BY-NC 4.0) license, which permits others to distribute, remix, adapt, build upon this work non-commercially, and license their derivative works on different terms, provided the original work is properly cited, appropriate credit is given, any changes made indicated, and the use is non-commercial. See: http://creativecommons.org/licenses/by-nc/4.0/.

\section{REFERENCES}

1. NCD Risk Factor Collaboration (NCD-RisC). Trends in adult bodymass index in 200 countries from 1975 to 2014: a pooled analysis of 1698 population-based measurement studies with $19 \cdot 2$ million participants. Lancet 2016;387:1377-96.

2. Mensink GBM, Schienkiewitz A, Haftenberger M, et al. Overweight and obesity in Germany: Results of the German Health Interview and Examination Survey for Adults (DEGS1). Bundesgesundheitsblatt Gesundheitsforsch - Gesundheitsschutz 2013;56(5-6):786-94.

3. Varnaccia G, Zeiher J, Lange C, et al. Factors influencing childhood obesity - the establishment of a population-wide monitoring system in Germany. J Heal Monit 2017;2:85-97.

4. World Health Organization. The Challenge of Obesity in the WHO European Region and the Strategies for Response [Internet]. http:// content.wkhealth.com/linkback/openurl?sid=WKPTLP:landingpage\& an=00005768-200803000-00031 (accessed 9 January, 2018).

5. Weiner B, Perry RP, Magnusson J. An attributional analysis of reactions to stigmas. J Pers Soc Psychol 1988;55:738-48.

6. Puhl RM, Heuer CA. Obesity stigma: important considerations for public health. Am J Public Health 2010;100:1019-28.

7. Link BG, Phelan JC. Conceptualizing Stigma. Annu Rev Sociol 2001;27:363-85.

8. World Health Organization. Obesity and overweight [Internet]. http:// www.who.int/mediacentre/factsheets/fs311/en/ (accessed 9 January, 2018).

9. Puhl R, Brownell KD. Bias, discrimination, and obesity. Obes Res 2001:9:788-805.

10. Puhl RM, Heuer CA. The stigma of obesity: a review and update. Obesity 2009;17:941-64.

11. Sikorski C, Luppa M, Glaesmer $\mathrm{H}$, et al. Attitudes of health care professionals towards female obese patients. Obes Facts 2013;6:512-22.

12. Hilbert A, Rief W, Braehler E. Stigmatizing attitudes toward obesity in a representative population-based sample. Obesity 2008;16:1529-34.

13. Mata J, Hertwig R. Public Beliefs About Obesity Relative to Other Major Health Risks: Representative Cross-Sectional Surveys in the USA, the UK, and Germany. Ann Behav Med 2018;52:273-86.

14. Sikorski C, Luppa M, Angermeyer MC, et al. The association of $\mathrm{BMI}$ and social distance towards obese individuals is mediated by sympathy and understanding. Soc Sci Med 2015;128:25-30.

15. Himmelstein MS, Puhl RM, Quinn DM. Intersectionality: An Understudied Framework for Addressing Weight Stigma. Am J Prev Med 2017;53:421-31.

16. Puhl RM, Andreyeva T, Brownell KD. Perceptions of weight discrimination: prevalence and comparison to race and gender discrimination in America. Int J Obes 2008;32:992-1000.
17. Tang-Péronard JL, Heitmann BL. Stigmatization of obese children and adolescents, the importance of gender. Obes Rev 2008;9:522-34.

18. Almenara CA, Ježek $\mathrm{S}$. The source and impact of appearance teasing: an examination by sex and weight status among early adolescents from the Czech Republic. J Sch Health 2015;85:163-70.

19. Fikkan JL, Rothblum ED. Is Fat a Feminist Issue? Exploring the Gendered Nature of Weight Bias. Sex Roles 2012;66:575-92.

20. Hebl MR, Turchin JM. The Stigma of Obesity: What About Men? Basic Appl Soc Psych 2005;27:267-75.

21. Slater LZ, Moneyham L, Vance DE, et al. The multiple stigma experience and quality of life in older gay men with HIV. J Assoc Nurses AIDS Care 2015;26:24-35.

22. Grollman EA. Multiple disadvantaged statuses and health: the role of multiple forms of discrimination. J Health Soc Behav 2014;55:3-19.

23. Radcliffe J, Doty N, Hawkins LA, et al. Stigma and sexual health risk in HIV-positive African American young men who have sex with men. AIDS Patient Care STDS 2010;24:493-9.

24. Puhl RM, Luedicke J, Heuer CA. The stigmatizing effect of visual media portrayals of obese persons on public attitudes: does race or gender matter? J Health Commun 2013;18:805-26.

25. Gray L. Social Determinants of Health, Disaster Vulnerability, Severe and Morbid Obesity in Adults: Triple Jeopardy? Int J Environ Res Public Health 2017;14:1452.

26. Mackenbach JP, Stirbu I, Roskam AJ, et al. Socioeconomic inequalities in health in 22 European countries. $N$ Engl $\mathrm{J} \mathrm{Med}$ 2008;358:2468-81.

27. Kuntz B, Lampert T. Socioeconomic factors and obesity. Dtsch Ärzteblatt Int 2010;107:517-22.

28. infas [Institute for Applied Social Sciences]. [About every tenth person without landline in household] [Internet] https://www.infas.de/ fileadmin/user_upload/PDF/infas_PM_Mobile_Onlys_Kommunikatio nsmonitor.pdf (accessed 9 January, 2018).

29. Kish L. A Procedure for Objective Respondent Selection within the Household. J Am Stat Assoc 1949;44:380-7.

30. Knesebeck OVD, Kofahl C, Makowski AC. Differences in depression stigma towards ethnic and socio-economic groups in Germany - Exploring the hypothesis of double stigma. J Affect Disord 2017:208:82-6.

31. Makowski AC, Mnich EE, Ludwig J, et al. Changes in beliefs and attitudes toward people with depression and schizophrenia - results of a public campaign in Germany. Psychiatry Res 2016;237:271-8

32. Schlinzig T, Schneiderat G. Possibilities to increase availability in telephone surveys. In: Weichbold M, Bacher J, Wolf C, eds. Survey Research: Challenges and Limits. Wiesbaden: VS Verlag für Sozialwissenschaften, 2009:21-43

33. Evans SC, Roberts MC, Keeley JW, et al. Vignette methodologies for studying clinicians' decision-making: Validity, utility, and application in ICD-11 field studies. International Journal of Clinical and Health Psychology 2015;15:160-70.

34. Schomerus $\mathrm{G}$, Matschinger $\mathrm{H}$, Angermeyer MC. Continuum beliefs and stigmatizing attitudes towards persons with schizophrenia, depression and alcohol dependence. Psychiatry Res 2013;209:665-9.

35. Sikorski C, Luppa M, Brähler E, et al. Obese children, adults and senior citizens in the eyes of the general public: results of a representative study on stigma and causation of obesity. PLoS One 2012;7:e46924

36. Bacon JG, Scheltema KE, Robinson BE. Fat phobia scale revisited: the short form. Int J Obes Relat Metab Disord 2001;25:252-7.

37. Robinson BE, Bacon JG, O'Reilly J. Fat phobia: measuring, understanding, and changing anti-fat attitudes. Int J Eat Disord 1993;14:467-80.

38. Stein J, Luppa M, Ruzanska U, et al. Measuring negative attitudes towards overweight and obesity in the German population psychometric properties and reference values for the German short version of the Fat Phobia Scale (FPS). PLoS One 2014;9:e114641.

39. Puhl RM, Luedicke J, Heuer C. Weight-based victimization toward overweight adolescents: observations and reactions of peers. J Sch Health 2011;81:696-703.

40. Angermeyer MC, Holzinger A, Matschinger $\mathrm{H}$. Emotional reactions to people with mental illness. Epidemiol Psichiatr Soc 2010;19:26-32.

41. Link BG, Cullen FT, Frank J, et al. The social rejection of former mental patients: understanding why labels matter. Am J Sociol 1987;92:1461-500.

42. Bogardus E. Measuring social distance. J App/ Sociol 1925:9:299-308

43. IBM. SPSS Statistics for Windows. Armonk, NY: IBM Corp, 2013.

44. Intenational Labour Office. International Standard Classification of Occupations: ISCO-08 [Internet]. http://www.ilo.org/wcmsp5/groups/ 
public/-dgreports/-dcomm/-publ/documents/publication/wcms 172572.pdf (accessed 9 January, 2018).

45. Statistisches Jahrbuch 2016. https://www.destatis.de/DE/ Publikationen/StatistischesJahrbuch/StatistischesJahrbuch2016. pdf?_blob=publicationFile (accessed 28 August, 2018).

46. Statistisches Bundesamt. Internet]. 2016 https://www.destatis. de/DE/ZahlenFakten/GesellschaftStaat/Bevoelkerung/ Bevoelkerungsstand/Tabellen/Zensus_Geschlecht Staatsangehoerigkeit.html (accessed 28 August, 2018).

47. Crenshaw K. Demarginalizing the intersection of race and sex: a black feminist critique of antidiscrimination doctrine, feminist theory and antiracist politics. Univ Chic Leg Forum 1989;139:139-67.
48. Brennan MA, Lalonde CE, Bain JL. Body Image Perceptions: Do Gender Differences Exist? Psi Chi Journal of Psychological Research 2010;15:130-8.

49. Grossbard JR, Neighbors C, Larimer ME. Perceived norms for thinness and muscularity among college students: what do men and women really want? Eat Behav 2011;12:192-9.

50. Boswell RG, White MA. Gender differences in weight bias internalisation and eating pathology in overweight individuals. $A d v$ Eat Disord 2015;3:259-68.

51. Briggs SR, Cheek JM. The role of factor analysis in the development and evaluation of personality scales. $J$ Pers 1986;54:106-48. 